\title{
Improved Damper Cage Design for Salient-Pole Synchronous Generators
}

\begin{abstract}
The benefits of implementing a damper winding in salient-pole, synchronous generators are widely known and well consolidated. It is also well known that such a winding incurs extra losses in the machine due to a number of reasons. In order to improve the overall efficiency and performance of classical salientpole, wound field, synchronous generators that employ the traditional damper cage, an improved amortisseur winding topology that reduces the inherent loss is proposed and investigated in this paper. This is essential in order to meet modern power quality requirements and to improve the overall performance of such 'classical' machines. The new topology addresses the requirements for lower loss components without compromising the acceptable values of the output voltage total harmonic distortion and achieves this by having a modulated damper bar pitch. As vessel for studying the proposed concept, a $4 M V A$, salient-pole, synchronous generator is considered. A finite element model of this machine is first built and then validated against experimental results. The validated model is then used to investigate the proposed concept with an optimal solution being achieved via the implementation of a genetic algorithm optimization tool. Finally, the performance of the optimised machine is compared to the original design both at steady state and transient operating conditions.
\end{abstract}

\section{INTRODUCTION}

Due to its excellent characteristics and proven performance capability, the salient-pole, field wound, synchronous generator (SG) has a long history of utilisation in the field of power generation [1], [2]. Although these 'classical' electrical machines have been extensively studied and implemented, today there is an interest in revamping their design and development, partly due to the ever-increasing requirements in terms of power quality standards, efficiency and grid compliance and partly due to advances in materials and manufacturing techniques. Also, the significant improvements in the computational resources allow the utilisation of modern design techniques and tools such as multi-physics modelling [3] and virtual prototyping [4].

In order to consider efficiency and power quality constraints, particular focus in recent years has been given to the functional behaviour and design features of the damper winding. This consists of bars placed in slots in the pole faces and connected together at each end. The end conductors in a complete damper winding are closed rings (or sometimes end laminations) connecting the bars of all the poles, while in an incomplete damper winding they are electrically discontinued between poles. Complete damper windings are similar to the squirrel-cage of an induction machine [5]. The main reasons for providing a damper cage on salient-pole synchronous generators, as summarized in [6], are

- providing starting torque for synchronous motors, condensers and converters;

- suppress hunting due to the pulsating torque of the engines;

- damping oscillations caused by aperiodic shocks, such as short-circuits;

- balancing terminal voltages during unbalanced loading;

- preventing overheating of the pole tips of single-phase generators;

- providing braking torque on a generator during an asymmetrical fault;

- providing additional torque for synchronizing generators;
- reducing the stress on the insulation of the field winding during current surges in the armature windings;

- preventing distortion of voltage waveform; in other words, to suppress harmonics.

Additional losses in the damper winding are due to parasitic harmonics in the air-gap flux density. As stated in [7], these harmonics are generated by the following:

- Tooth-ripple, due to the open slot structure typical of highvoltage machines;

- Armature reaction magneto-motive force, which causes parasitic harmonics on the rotor surface when currents flow in the stator windings;

- Unbalanced air-gap, which can induce high bar currents.

Traditionally, the design of damper windings has been done by means of conventional methods which combine theoretical and empirical techniques. Early works focused on the prediction of the damper-bar currents with the classical dq equivalent circuit approach [8], [9]. With the same purpose, permeance models based on Fourier expansion are used in [10] and [11]. In [7] an innovative numerical integration method is proposed and also compared with the traditional dq-axis approach with very positive results. Although the worth of these traditional techniques is well known and consolidated, with the recent advancements in computational capabilities, a significant shift towards numerical methods, such as finite-element (FE) and computational fluid dynamics [12], [13], allows for improved accuracy and extra degrees of freedom in the design process. Due to this, today there is an increasing interest in the damper winding designs (and SGs in general [14]), as this can be very beneficial to the overall SG performance. This is very important especially when considering the possibility to investigate the machine operation both in steady-state and in transient conditions. In particular, "complete" and "incomplete" end connections are analysed in [15] and [16], where the effects on the generator performance of various damper cage designs were investigated. In [17] and [18], FE analyses are used to predict and optimize the no-load voltage waveform. For example, [19] shows how improvements in the voltage output shape are achieved by inducing additional currents in the bars of the damper winding at the cost of increased losses and thermal issues.

In this work, a new damper cage topology is proposed to address the requirements for the output voltage Total Harmonic Distortion (THD), without compromising the power loss associated with this winding. The proposed techniques are considered on an existing machine platform in the form of a $4 M V A \mathrm{SG}$. The SG in question is presented in Section II, where it can be seen how this machine exhibits high rotor losses, making it an ideal vessel for the work proposed in this project. As a first step, a complete FE analysis of the current machine is done and compared with available experimental results, obtained from the prototype shown in Fig. 19. The FE model is then used to propose, investigate and validate a number of techniques to improve the overall SG performance. However, the main objective of this work is to provide an alternative solution to the state-of-the-art, aimed at reducing damper winding loss at 
steady-state operation while keeping the no-load voltage THD under permissible limits. A Genetic Algorithm (GA) based optimization is carried out in order to achieve an optimal solution.

\section{AnAlysis And VAlidation of the Model of the SG TEST PLATFORM}

The salient-pole SG under analysis is a four pole alternator designed for standalone power applications. The machine has a rated apparent power of $4 M V A$ at 0.8 power factor. The generator is designed to provide a three-phase output voltage of $11 \mathrm{kV}$ at $50 \mathrm{~Hz}$. Some of the major features of the SG under study are as follows:

- the stator is laminated and has a open-slot structure;

- stator coils are grouped in 2 parts, having different number of turns to reach a certain desired magneto-motive force;

- there are no parallel circuits on the stator windings;

- the stator core is equipped with radial ventilating ducts along the axial direction; these reduce the active material of the machine but improve cooling and airflow;

- the rotor is also laminated and made by the same electromagnetic steel as the stator laminations;

- the ratio between the rotor diameter (in correspondence of the minimum airgap) and the axial length is 0.5 ;

- the damper cage on the rotor is displaced around the polar axis in alternating directions on each pole, as shown in Fig. 1, in order to improve the harmonic content of the output voltage waveform in the absence of rotor or stator skewing.

In SGs, the presence of ventilating ducts along the axial length, the damper winding, the rotor laminations support bars and their related stacking issues make the machine very complex to model and analyse. Other critical aspects are the leakage fluxes due to the end-windings and the presence of the end aluminium laminations needed to give continuity to the damper cage. To consider such machine aspects, a number of compensation factors are included in the FE model. In particular, whilst any contact between bars and laminations are considered negligible for the sake of this study, end connections are accounted for through circuital lumped resistances and calculated taking into account shape and thickness of the end aluminium laminations. This allows for a significant increase in the model's accuracy. Also, considering that the main investigation focuses on the damper windings, it was considered essential to model the amortisseur bars as accurately as possible. In fact, each bar is modelled as a solid conductor to take into account the skin effect due to the higher order slot harmonics [20], [21].

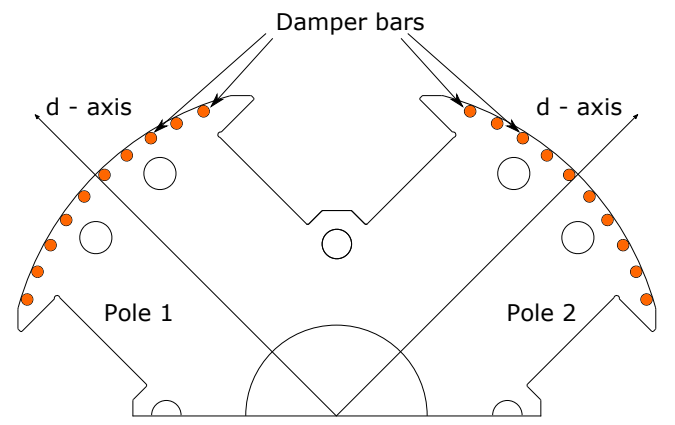

Fig. 1. Actual rotor topology with damper cage displaced around the polar axis (d-axis).

\section{A. No-Load and Short-Circuit Characteristics}

The open circuit characteristic is found by measuring the no-load terminal voltage at different levels of field current. Although static simulations (phase $\mathrm{A}$ axis and d-axis parallel) are suggested in [22] in order to reduce the required computational resources, in this case transient with motion simulations were used as these fully consider the harmonic content of the no-load voltage. Fig. 2 compares the FE results with the experimental measurements on the prototype. It can be noticed that the transient simulation curve is almost exactly matching the experimental result.

The Short-Circuit (SC) characteristic is determined by measuring the steady-state currents at different levels of field current after a sudden three-phase short-circuit fault at the generator terminals. Always referring to Fig. 2, a good agreement between $\mathrm{FE}$ and experimental results can be observed.

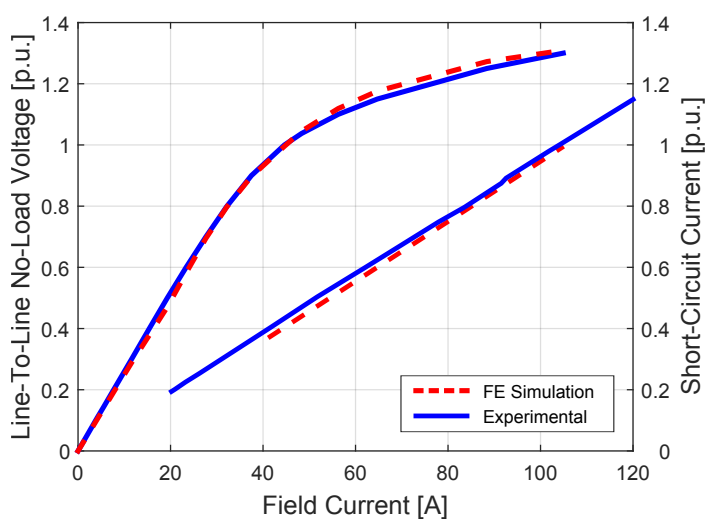

Fig. 2. No-load and short-circuit characteristics: comparison between FE and experimental results.

\section{B. Full-Load Analysis}

In Fig. 3, a field map of the synchronous generator under analysis at full-load rated conditions is shown. The effect of the transversal armature field component on the excitation field (due to the ohmic-inductive nature of the rated load) can be observed. Depending on the required loading and power factor, the rotor

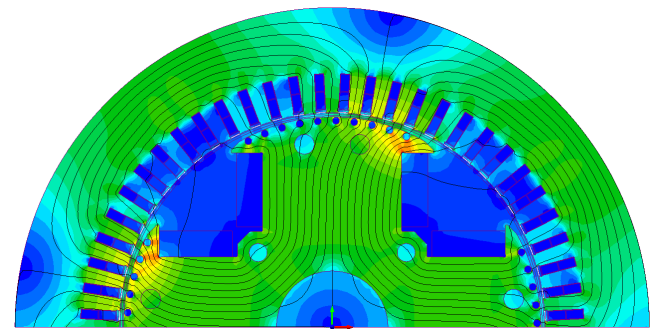

Fig. 3. Field map at full-load operation.

currents and the passive components values can be set to run a transient simulation, until the steady-state condition is reached. Table I compares the experimental and FE results for the full load rated condition, with the rated field current being used in the 2D FE model and an excellent similarity being achieved.

\section{Power Losses}

In general, power losses in electrical machines are composed by the following terms:

- Resistive losses in stator and rotor conductors;

- Iron losses in ferromagnetic materials;

- Mechanical losses, i.e. windage and friction. 
TABLE I

FULL-LOAD RESULTS

\begin{tabular}{cccc}
\hline $\begin{array}{c}\text { Electromagnetic } \\
\text { Quantities }\end{array}$ & $\begin{array}{c}F E \\
\text { Results }\end{array}$ & $\begin{array}{c}\text { Experimental } \\
\text { Results }\end{array}$ & $\begin{array}{c}\text { Percentage } \\
\text { Error }\end{array}$ \\
\hline Field Current & $143.7 \mathrm{~A}$ & $143.7 \mathrm{~A}$ & $0 \%$ \\
\hline Load Voltage & $10998 \mathrm{~V}$ & $11000 \mathrm{~V}$ & $0.02 \%$ \\
\hline Phase Current & $230.2 \mathrm{~A}$ & $233.6 \mathrm{~A}$ & $1.46 \%$ \\
\hline Power Factor & 0.802 & 0.8 & $0.25 \%$ \\
\hline Real Power & $3.51 \mathrm{~kW}$ & $3.56 \mathrm{~kW}$ & $1.46 \%$ \\
\hline
\end{tabular}

The SG being considered in this paper comprises the presence of ventilating ducts on the stator. Thus, in order to consider the parts of the windings which are present along these ducts, an additional lumped resistance is added to the model. This also is used to take into account the end-winding effects, which can be important especially when using 2D models. Simple corrections are included to account for the temperature effects on the copper conductivity. Based on this, it can be inferred that the resistances considered in the FE model are very close to the experimental ones. Therefore, while very small differences are detected for the field winding losses, the discrepancy between FE and experimentally determined currents reflects on the stator resistive loss. Fig. 4 shows a comparison between FE and experimental copper losses, at different loadings and power factors, where the percentage error at rated full-load condition is $5.46 \%$ for the stator loss. Core losses are experimentally measured at

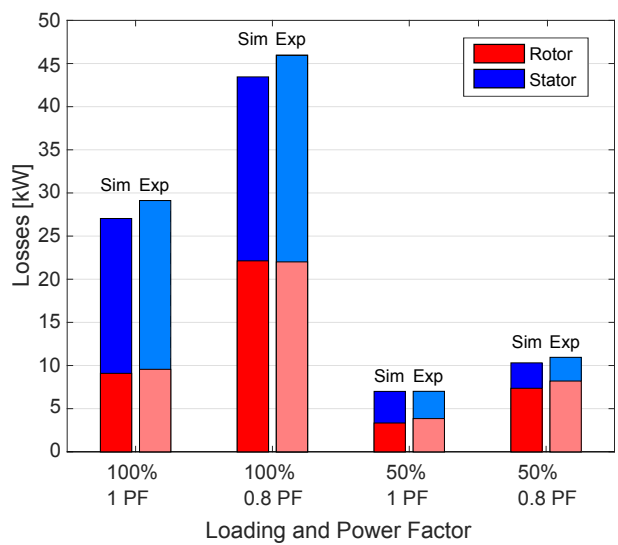

Fig. 4. Copper losses at different load levels and power factors: comparison between FE and experimental results.

no-load and then assumed approximately constant for all load levels and power factors. Traditionally only the total core loss is determined as any localisation exercise to determine where the loss actually is (rotor or stator or damper) is very difficult to do. Although damper winding losses are of ohmic-resistive nature, they are included in the experimentally measured values. Numerical methods usually employ the Steinmetz equation [23] to determine iron losses. In this work, an algorithm based on Steinmetz equations but extended to all the harmonics [24] is proposed and implemented. Hence, surface losses due to the slot harmonics are properly considered over the whole amount of iron loss. The computation algorithm of the iron losses can be summarised in the followings:

- A transient with motion 2D finite-element analysis is performed.

- From the magnetic field solution, the flux-density waveform is extracted corresponding to an electric cycle for each element from the iron regions, i.e. the stator and rotor steel.
- The Fourier-series decomposition is applied for all the fluxdensity waveforms. The first 100 harmonics are considered, in order to account for the slotting effect on the loss computation.

- The following equations are then used to compute the hysteresis and eddy current components in each element of the iron regions:

$$
\begin{gathered}
P_{\text {iron }}=P_{\text {hyst }}+P_{\text {eddy }} \\
P_{\text {hyst }}=k_{h} \sum_{i=1}^{N}(i f) B_{i}^{\alpha} \\
P_{\text {eddy }}=k_{e} \sum_{i=1}^{N}(i f)^{2} B_{i}^{2}
\end{gathered}
$$

where $f$ is the frequency, $B$ the peak flux density, $k_{h}$ and $k_{e}$ are the hysteresis and the eddy current loss coefficients respectively, and $\alpha$ is the Steinmetz constant. These coefficients are determined through curve fitting techniques, by using the data available from test previously carried out on an Epstein frame for obtaining the loss contribution separation.

- The summation of all the losses per element gives the total iron loss.

In Fig. 5, the losses computed by means of this algorithm, developed in [24] for different applications, can be observed at various loadings and power factors. It can be observed that iron losses are essentially constant in relation to loading and power factor, while damper cage loss significantly varies with respect to the same aspects. In order to be coherent with the

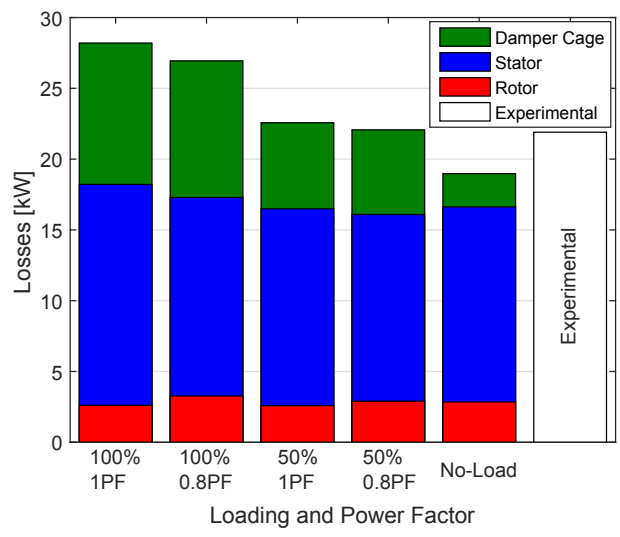

Fig. 5. Iron losses at different load levels and power factors.

experimental loss determination, the measured and predicted losses are compared only for the no-load condition. A very good similarity between FE and experimental results is observed, with a percentage error of less than $13 \%$ being achieved.

\section{Conclusive considerations on the FE model}

Although a 3D model [25], [26] would be ideal for the electromagnetic analysis of the generator described in this section, all the above confirms the validity of the built $2 \mathrm{D} \mathrm{FE}$ model of the $4 M V A$ salient-pole SG. As can be observed, the obtained FE results, when compared to the experimental ones, give an accurate match at each load condition. Fig. 2 shows a comparison in terms of no-load and short-circuit characteristics. From Table I, a very good agreement can be observed in terms of full-load results. The FE and experimental copper and iron losses are also compared and successfully validated for different loadings and power factors. 


\section{DAMPER CAGE SENSITIVITy ANALYSiS}

Having thus validated the FE model, the next step is to start focusing more in detail on the damper cage loss. From Fig. 5, it can be observed how the damper cage loss is a very important contributor to the SG total loss. In particular, almost $30 \%$ of the total amount of rotor loss at no-load condition is due to the damper winding and about the $27 \%$ at full-load rated condition. One of the main reasons for these elevated values of losses is the open slot geometry of the stator of the particular SG. As can be observed in Fig. 6, such a design indicates large variations in the air-gap flux (under the slot openings). The damper cage reaction to these variations results in excessive induced current flows in its bars, thus a considerable resistive loss is always present in the damper cage, even during steady state. Preliminary geometrical considerations were carried out

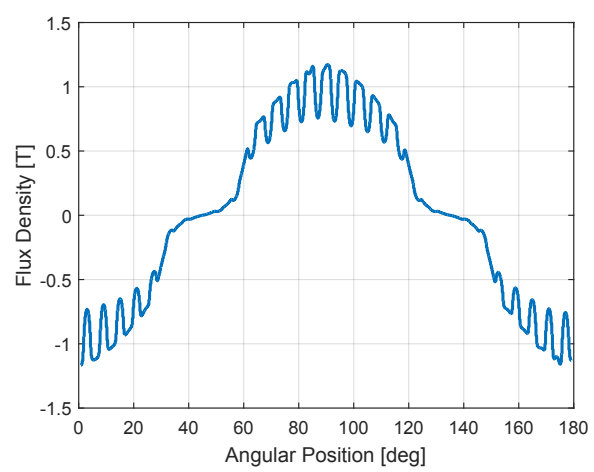

Fig. 6. No-load radial air-gap flux density.

to justify the fact that no lumped components are considered in the model to account for the bar connection plate resistance and inductance. An equivalent copper conductivity is utilized to account for the temperature at which the damper cage is working at each simulated load condition.

\section{A. Key Parameters}

A preliminary sensitivity analysis is essential to work out the parameters that are most sensitive to damper cage loss and voltage THD variations. The results shown in this section are therefore introductory to set-up the optimization procedure described in Section IV. The main key parameters whose effects are investigated are:

- the magnetic permeability of the stator slot wedge;

- the bar pitch;

- the asymmetric displacement of damper bars along the tangential direction.

\section{B. Influence of slot wedge permeability}

One way to reduce the heavy "slotting" effect on the air-gap flux density is by using a different material for the slot wedge [27]. In the actual machine, the material employed as stator slot wedge is Magnoval Fe70, with a relative magnetic permeability $\mu_{r}=2.5$. By increasing the magnetic permeability of the slot wedge material, the slotting effect considerably decreases [28] on both the rotor surface and the damper bars. Indeed the higher the permeability, the more isotropic is the stator surface which faces the main air-gap. The overall effect of this aspect was investigated by testing the FE model of the 4MVA SG for a number of different slot wedge materials each with its own permeability value. This determines a reduction of damper cage losses. The overall effect of this aspect was investigated by testing the FE model of the 4MVA SG for a number of different
TABLE II

Losses And THD vs. Magnetic Wedge Permeability.

\begin{tabular}{l|lll}
\hline Permeability & \multicolumn{2}{|c}{ Damper cage Losses } & No Load $V$ \\
\hline$\mu_{r}$ & No Load [W] & Full Load [W] & THD [\%] \\
\hline 2.5 & 2351 & 9653 & 2.57 \\
5 & 1832 & 6431 & 2.05 \\
8 & 1521 & 5601 & 1.83 \\
10 & 1398 & 5362 & 1.75 \\
13 & 1274 & 5096 & 1.68 \\
16 & 1191 & 4978 & 1.63 \\
\hline
\end{tabular}

slot wedge materials, each with its own permeability value. The results are summarized in Table II, reporting the damper cage losses calculated at no-load and full-load condition respectively. For each case, the no-load line-to-line voltage THD has been computed as shown in the fourth column. The relative magnetic permeability is ranging from 2.5 to 16 , all corresponding to Magnoval-based materials but with a different composition. At no-load condition, the cage losses are decreasing as the magnetic permeability of the slot wedge material increases. It can be noted that the major relative improvement is given by using a magnetic wedge with a relative permeability of 5 taking to a damper cage loss reduction of $23 \%$. A further improvement could be achieved using a magnetic wedge with $\mu_{r}=10$, with a reduction of the losses by $40 \%$. Similar consideration can be evinced at full-load condition, where the damper cage losses are reduced by almost $33 \%$ if $\mu_{r}=5$ and by about $42 \%$ if a material with a relative permeability of 8 or 10 is used. In both cases, a further increase in $\mu_{r}$ does not relate to any significant reduction of losses. A THD reduction of the no-load line-to-line voltage can also be observed in Table II.

The main drawback of increasing the permeability is the increase of slot flux leakage especially at full-load operating condition. This results in less useful flux crossing the air-gap and consequently a higher voltage drop and a torque reduction. Comparing the results of tests performed with $\mu_{r}=2.5$ and $\mu_{r}=16$ materials, a voltage drop of $5 \%$ is found. This can be compensated by an increase of the excitation current, however at the cost of extra copper losses, which in turn can potentially negate the positive effect of having a higher permeability slot wedge material. All the above confirms that significant advantages can be achieved by choosing an appropriate material for the slot wedges, where it is advised to design for a good balance between the quality of the air-gap flux density and the resulting slot flux leakage.

\section{Influence of bar pitch}

Another important player in terms of damper cage losses is the effect due to the pitch of the damper bars $\vartheta_{d}$, which strongly relates to the stator slot pitch $\vartheta_{s}$. Traditionally, this is chosen by applying well-known empirical rules, e.g. it can be varied from $0.8 \vartheta_{s}$ to $1.2 \vartheta_{s}$. However, with detailed modern numerical techniques, this also can be analysed more in detail and potentially improved by a considerable margin. Thus, in order to fully understand this aspect, the FE model of the 4MVA, SG is modified by varying the bar pitch with the damper cage being kept symmetric in respect to the polar axis. The results show no significant improvements respect to the case where the original bar pitch is used. On the contrary, the current bar pitch (i.e. $5.7 \mathrm{deg}$ ) is the most appropriate in terms of loss reduction, as one may note in Fig. 7 . 


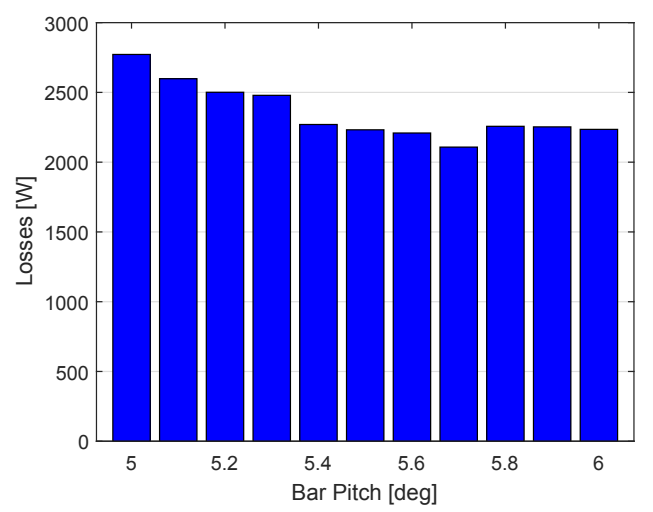

Fig. 7. No-load damper cage losses vs. bar pitch.

\section{Influence of asymmetric bar displacement}

In order to improve the voltage total harmonic distortion, the damper cage can be displaced by a particular angle, usually chosen as a fraction of the stator slot pitch, in respect to the polar axis. Some considerations on improved design and analysis of this aspect are presented in [29], with main focus on the improvement of the machine voltage THD, with no consideration for reducing losses. This geometrical feature can be seen in Fig. 8, where the damper bars are displaced in an asymmetric form over the rotor poles. In the case of the generator being studied in this paper, the actual configuration is the one shown in Fig. 8a). In order to investigate the effects that the asymmetry has on both the total amount of losses in the damper cage and voltage THD, a number of tests using different positions along the azimuthal direction are performed. In particular, the damper cage angle are varied from -1.68 deg (corresponding to the original displacement) to $+1.68 \mathrm{deg}$ (corresponding to the position shown in Fig. 8 c). From Fig. 9 and 10 , it can be observed that a symmetrical configuration (position 0 deg, as shown Fig. 8 b) presents the lowest cage loss respect to the other tangential positions, but at the same time results in a THD of about 7\%, which for the application at hand is not acceptable. On the other side, the original damper winding position is the only one that achieves a THD lower than 3\%. Even considering the importance of having a low THD for this application, this is still not an optimal solution because, as shown in Fig. 9, it also presents considerable damper winding ohmic losses, resulting in more heat generation and consequently a deterioration of the total machine efficiency. In particular, with respect to the symmetrical case, losses are increased by $15 \%$.

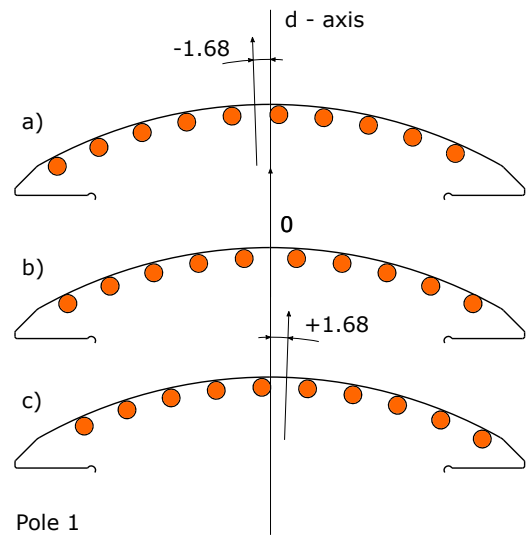

Fig. 8. Different damper cage positions shifted by: a) $-1.68 \mathrm{deg}$, b) $0 \mathrm{deg}$ (symmetrical case) and c) $+1.68 \mathrm{deg}$ with respect to the polar axis.

Considering all the above, then it is clear that while the orig-

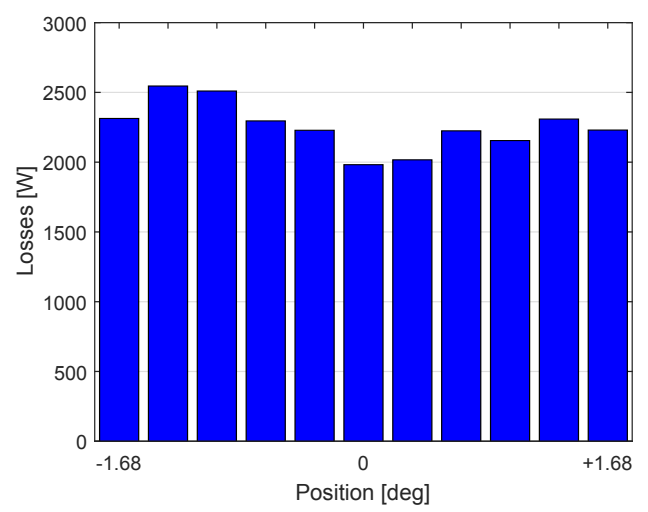

Fig. 9. No-load damper cage loss vs. tangential position.

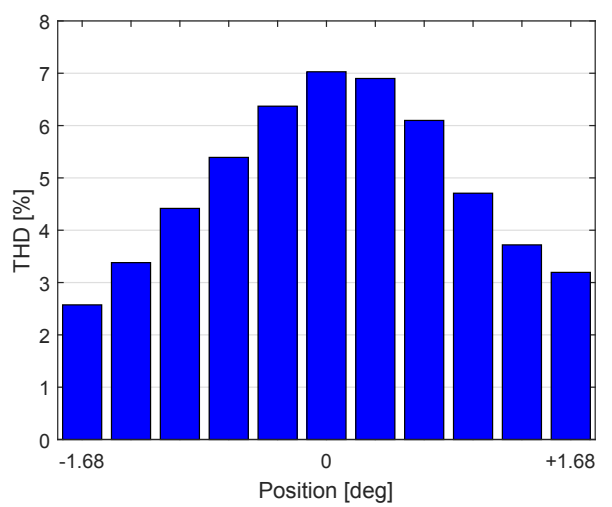

Fig. 10. No-load voltage THD vs. tangential position.

inal design of the damper cage meets some of the requirements (THD $<3 \%$ ), significant margins of improvement (mainly in terms of reducing losses) can be achieved.

\section{Modulated Damper Cage Optimization}

All the above studies show that for certain aspects there is significant room for improvement by modifying the design of the damper cage windings. As a means to reduce these losses in the damper winding, whilst maintaining the voltage THD at an acceptable limit, it is proposed to modify the positioning of the bars in the context of having a modulated bar pitch. This concept consists of having unconventionally displaced damper bars along the salient pole. In other words, when the bar pitch $\beta_{i}$ is constant and equal to $\beta_{i+1}$, with $i=0, . ., 9$, the damper cage is equally distributed. When the bar pitch is variable, with $\beta_{i} \neq \beta_{i+1}$, the winding can be called "modulated damper cage" and looks like the scheme illustrated in Fig. 13b). By applying this solution to the particular SG analysed, the irregular damper bar pitch interacts with the stator open slot structure in such a way that the air-gap parasitic harmonics are reduced. Although the concept of having asymmetrical windings has been already implemented in asynchronous machines [30], such a methodology has not been applied to address losses and THD improvements in SGs.

\section{A. Preliminary Analytical Considerations}

The equivalent circuit methodology is a classical approach for modelling electromagnetic phenomena in electrical machines. In particular, SGs models which include the rotor damper winding consist of ' $m+b+2$ ' circuits magnetically coupled to each other, where $m$ and $b$ are the number of stator phases and rotor bars, respectively. It is common to model the damper cage as ' $b+1$ ' loops [31], thus allowing to derive the voltage equations in the matrix form as given in (4), where the vector $\bar{i}$ represents 
the currents flowing in the phases and $\bar{\psi}$ the fluxes linking with the phases.

$$
\bar{v}=R \bar{i}+\frac{d \bar{\psi}}{d t}
$$

Neglecting the saturation effects in the soft magnetic parts of the machine, the analysis can then be dealt with as magnetically linear and (4) can be developed and described by (5).

$$
\bar{v}=R \bar{i}+\left(\frac{\delta L(\alpha)}{\delta \alpha} \bar{i}\right) \frac{d \alpha}{d t}+L(\alpha) \frac{d \bar{i}}{d t}
$$

In equation (5), $\alpha$ is the mechanical variable associated with the rotor position, and $R$ and $L$ are $(m+b+1) *(m+b+1)$ matrices containing all the resistances, and the self- and mutualinductances that characterise the machine. It can also observed that, if the phase resistances and the state variables (i.e. currents and position) are known, then the machine performance is directly related to the inductance matrix.

An expression for the inductance, based on the application of the winding function method [32], is provided in (6) [33], where $l$ is the axial length of the machine, $\lambda$ the angular reference frame locked to the rotor and normalised over the electrical period and $\bar{N}_{E}$ the vector of the equivalent winding functions of the phases. The equivalent winding function $N_{E j}(\lambda, \alpha)$ of the generic phase $j$ is defined by the difference between the known winding function $N_{j}(\lambda, \alpha)$ and its mean value weighted over the equivalent permeability function $\mu_{E}(\lambda, \alpha)$, which is given in (7).

$$
\begin{gathered}
L(\alpha)=l \int_{0}^{1} \mu_{E}(\lambda, \alpha) \bar{N}_{E}(\lambda, \alpha) \bar{N}_{E}^{T}(\lambda, \alpha) d \lambda \\
\mu_{E}(\lambda, \alpha)=\mu_{0} \frac{2 \pi r_{G}(\lambda, \alpha)}{\epsilon_{G}(\lambda, \alpha)}
\end{gathered}
$$

In (7), $\mu_{0}$ is the permeability of the free space, and $r_{G}(\lambda, \alpha)$ and $\epsilon_{G}(\lambda, \alpha)$ represent the air-gap radius and thickness, respectively along the tangential direction. Hence, (7) contains all the information regarding the anisotropies present in the machine.

In order to investigate the slot ripple harmonics and their associated effects on the performance of the SG analysed in this paper, (6) needs to be further elaborated. As the SG exhibits an intrinsic symmetry that turns into a periodical trend of $1 / p$ of all the quantities involved in (6), these can be developed into a Fourier series with respect to $\lambda$. The geometrical quantities involved in the $\mu_{E}(\lambda, \alpha)$ also have a periodicity which is half of that of the winding functions of the vector $\bar{N}_{E}(\lambda, \alpha)$. Hence, considering one generic element of the inductance matrix, (6) can be written as shown in (8).

$$
\begin{aligned}
L_{i j}(\alpha)= & l \int_{0}^{1}\left({ }^{0} \mu_{E}(\alpha)+\sum_{h=2}^{+\infty}{ }^{h} \mu_{E}(\alpha) \cos \left(2 \pi p h\left(\lambda-{ }^{h} \lambda_{E}(\alpha)\right)\right)\right) \\
& \times\left(\sum_{r=1}^{+\infty}{ }^{r} N_{i}(\alpha) \cos \left(2 \pi p r\left(\lambda-{ }^{r} \lambda_{i}(\alpha)\right)\right)\right) \\
& \times\left(\sum_{s=1}^{+\infty}{ }^{s} N_{j}(\alpha) \cos \left(2 \pi p s\left(\lambda-{ }^{s} \lambda_{j}(\alpha)\right)\right)\right) d \lambda
\end{aligned}
$$

Considering that the amplitudes of the Fourier components shown in (8) do not depend on the rotor position, then the final expression for the inductances can be written as given in (9).

$$
\begin{gathered}
L_{i j}(\alpha)=l\left(\sum_{h=1}^{+\infty} \frac{{ }^{0} \mu_{E}{ }^{h} N_{i}{ }^{h} N_{j}}{2} \cos \left(2 \pi p h\left({ }^{h} \lambda_{i}(\alpha)-{ }^{h} \lambda_{j}(\alpha)\right)\right)\right. \\
+\sum_{\substack{h, r, s=1 \\
h=s-r}}^{+\infty} \frac{{ }^{h} \mu_{E}{ }^{r} N_{i}{ }^{s} N_{j}}{4} \cos \left(2 \pi p \left(h{ }^{h} \lambda_{E}(\alpha)+r{ }^{r} \lambda_{i}(\alpha)\right.\right. \\
\left.\left.-s{ }^{s} \lambda_{j}(\alpha)\right)\right)+\sum_{\substack{h, r, s=1 \\
h=r-s}}^{+\infty} \frac{{ }^{h} \mu_{E}{ }^{r} N_{i}{ }^{s} N_{j}}{4} \cos \left(2 \pi p \left(h^{h} \lambda_{E}(\alpha)\right.\right. \\
\left.\left.-r^{r} \lambda_{i}(\alpha)+s{ }^{s} \lambda_{j}(\alpha)\right)\right)+\sum_{\substack{h, r, s=1 \\
h=r+s}}^{+\infty} \frac{{ }^{h} \mu_{E}{ }^{r} N_{i}{ }^{s} N_{j}}{4} \\
\left.\cos \left(2 \pi p\left(h{ }^{h} \lambda_{E}(\alpha)-r^{r} \lambda_{i}(\alpha)-s{ }^{s} \lambda_{j}(\alpha)\right)\right)\right)
\end{gathered}
$$

The last three summations in (9) show that only the harmonics that comply with the relationship $h \pm r \pm s=0$ contribute to the machine's inductances.

In the SG investigated in this paper, slot ripple harmonics are of critical importance. This information is contained in the function $\mu_{E}$, whose simplified shape is shown in Fig. 11. Considering all the above, it is clear that in order to reduce these

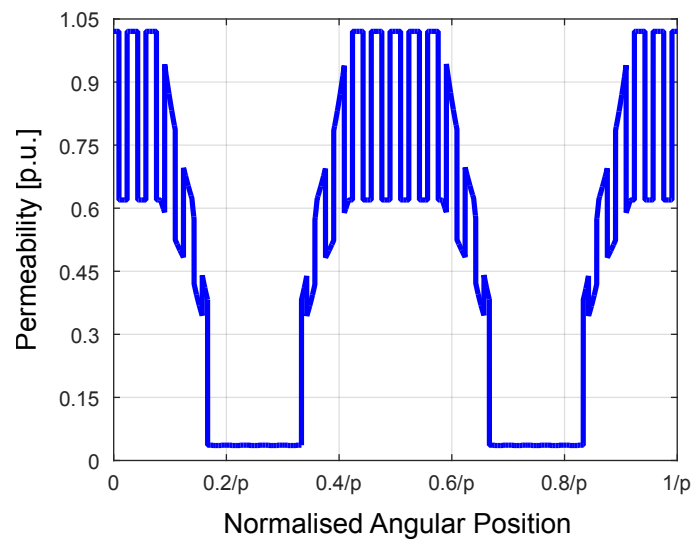

Fig. 11. Equivalent magnetic permeability function.

slotting effects, one may act on any of the quantities involved in (6). One possible option may be the repositioning of each damper bar along the salient poles of the machine, as this results in a modification of the following quantities:

- self- and mutual-inductances of the rotor damper windings $L_{b_{i} b_{j}}$;

- mutual-inductances between the damper windings and the stator circuits $L_{b_{i} s_{j}}$;

- mutual-inductances between the damper circuits and the field winding $L_{b_{i} r}$.

If (4) was to be written in its full form, it can then be observed that only the terms $L_{b_{i} s_{j}}$ can affect the stator voltages. However, all of these terms, i.e. $L_{b_{i} b_{j}}, L_{b_{i} s_{j}}$ and $L_{b_{i} r}$, can have an impact on the damper cage currents. If the amplitudes ${ }^{r} N_{i},{ }^{s} N_{j}$ and the phases ${ }^{r} \lambda_{i},{ }^{s} \lambda_{j}$ involved in (9) are modified, then this can potentially result in improvements of

- the stator voltage shape, by minimising the harmonic components whose order comply with the relationship $h \pm r \pm s=0$,

- the damper cage currents, by minimising the term $\frac{d \psi}{d t}$ present in (4) and developed in (5). 
An example of how one damper winding function can be modified by repositioning 2 bars is shown in Fig. 12. The effects of this modification on the amplitude and phase spectra of the winding function can also be observed.

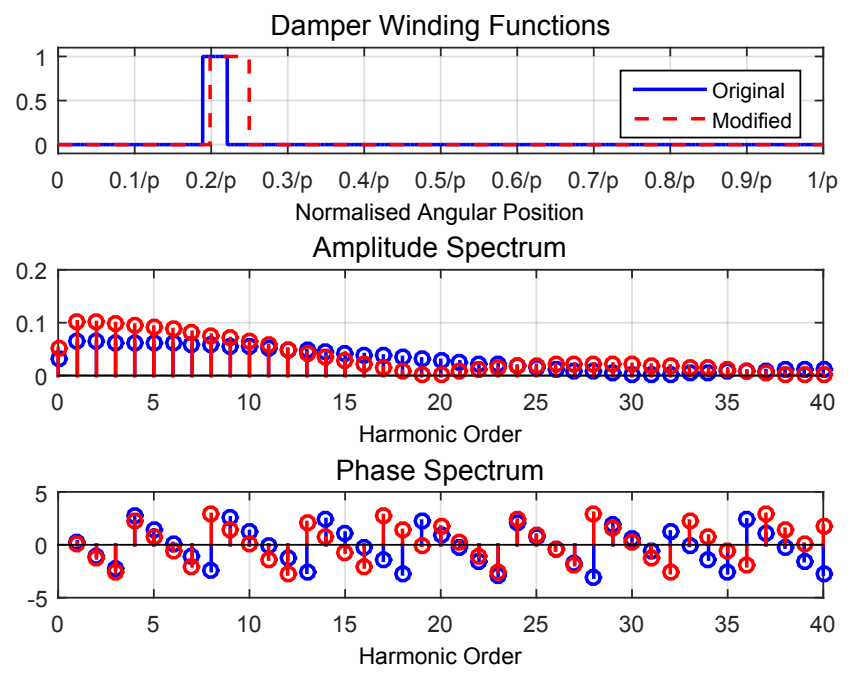

Fig. 12. Modulated damper winding function.

Considering the above preliminary analysis, it is clear that there is room for performance improvements by modulating the damper bar pitch of the $4 M V A$ SG. It can also be noticed that, due to the high number of bars per pole, there is a significant amount of combinations that can potentially result in THD and damper cage losses improvements. In order to achieve more accurate and reliable solutions, FE-based analysis is used to investigate all the possible configurations that the damper winding can assume. The optimal solution is achieved by carrying out GA- based optimisations, according to the procedure described below.

\section{B. Input Parameters}

In order to take advantage of the geometrical periodicities of the synchronous machine under analysis (i.e. to reduce computational times), odd periodic boundary conditions are used in the model and coupled to the damper winding circuit, in order to be consistent with the fact that the fields and signals should reverse when going from the modelled part of the device to one of its neighbouring un-modelled parts. Therefore, only $1 / 4$ of the machine is considered in the FE model. This results in only 10 design variables (one pole) being considered and used as input parameters. The design variables are shown in Fig. 13a). They are constrained in such a way that two consecutive bars never interfere with each other.

\section{Optimization Strategy}

The optimization process is initialised by a preliminary exploration of the design space. This phase is performed by using design of experiments (DoE) techniques [34], [35]. In particular, a design of experiments is used to find an assignment to each variable in such a way that all constraints are satisfied. Therefore an initial population of designs is provided to the optimization algorithm. The second phase of the procedure is performing a preliminary optimization by using a Multi-Objective GeneticAlgorithm (MOGA). This model uses a smart multi-search elitism that is able to preserve some excellent solutions without bringing premature convergence to local-optimal frontiers. Also, MOGA [36] requires only very few user-provided parameters,

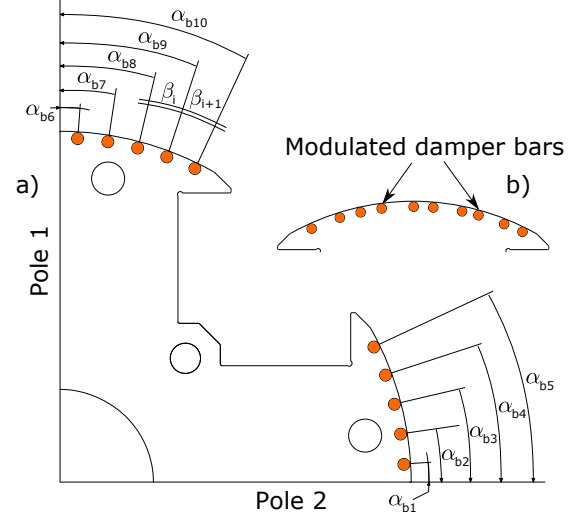

Fig. 13. Input parameters of the damper cage optimizations: a) $\alpha_{i}$ with $i=$ $1, . ., 10 ; \mathrm{b})$ modulated damper bar concept $\left(\beta_{i} \neq \beta_{i+1}\right)$.

several other parameters are internally settled in order to provide robustness and efficiency to the optimizer. In the end, a refinement is performed by using the best solutions of the previous iteration. Results have shown that only 2 iterations are sufficient to find an optimal solution.

\section{Output Variables}

As highlighted in the previous subsection, a multi-objective algorithm was used for investigating possible design solutions aimed at reducing the total amount of the damper cage loss and, at the same time, maintaining the THD of the no-load voltage the same as the original machine. Therefore, these 2 output variables were investigated and minimized by the optimization algorithm. All the FE-based tests were performed at no-load operating condition and the best solutions analysed at full-load in a successive step. Both the objectives have been constrained by the following expressions:

$$
\begin{gathered}
\sum_{i=1}^{n_{b}} R_{b_{i}} I_{b_{i}}^{2}<2000 W \\
100 \frac{\sqrt{\sum_{i=2}^{n_{h}} V_{i}^{2}}}{V_{1}}<3 \%
\end{gathered}
$$

The left hand sides of equations (10) and (11) represent the damper cage loss and the THD calculations, respectively. The right hand sides represent the imposed threshold values. In particular, in equation (10), $n_{b}$ is the total number of damping bars, $R_{b_{i}}$ the resistance of the $i$-bar that takes into account the skin effect due to parasitic harmonics, $I_{b_{i}}$ is the value of the current flowing into the $i$-bar once the steady-state is reached. In equation (11), $n_{h}$ is the number of harmonics used to evaluate the Fourier series decomposition of the no-load lineto-line voltage, whose fundamental is indicated as $V_{1}$ and higher harmonic components as $V_{i}$. Priority has been given to the loss minimization for which a threshold value lower than the actual no-load cage loss was assigned. On the other side, it is sufficient that the THD is kept under the permissible limit of $3 \%$.

\section{OPTIMIZATION RESULTS}

The results obtained from the modulated damper cage optimization are shown in Fig. 14. Few designs satisfy the objective constraints (10)-(11), as highlighted in the target area. Most of them have a damper cage design with similar geometry and therefore THD and losses are very close to each other. Among the best solutions, the one presenting the minimum amount of losses, whilst maintaining the same THD as in the current 


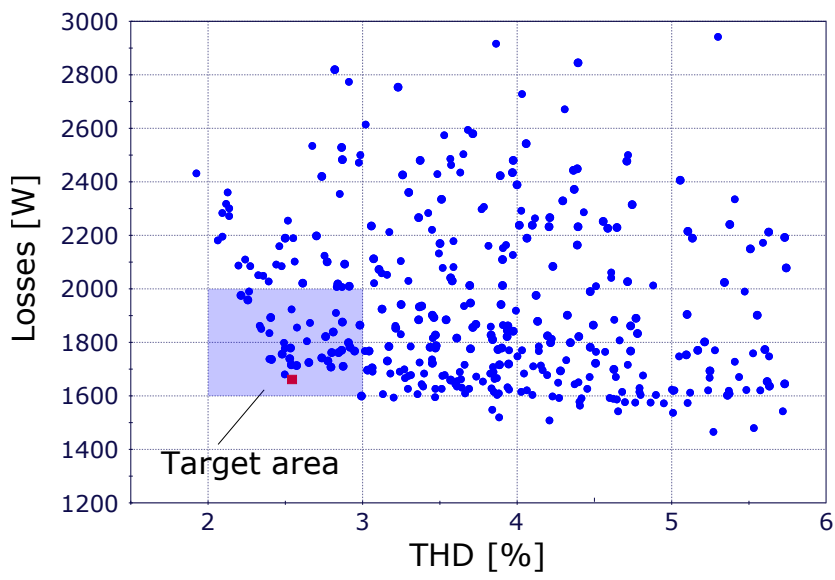

Fig. 14. No-load damper cage losses vs. THD: optimization solutions.

generator, has been selected for the comparison with the actual design. The rotor topology of the best machine obtained is highlighted in the red square (Fig. 14) and shown in Fig. 15, where the particular pattern of the bar pitch modulation can be observed.

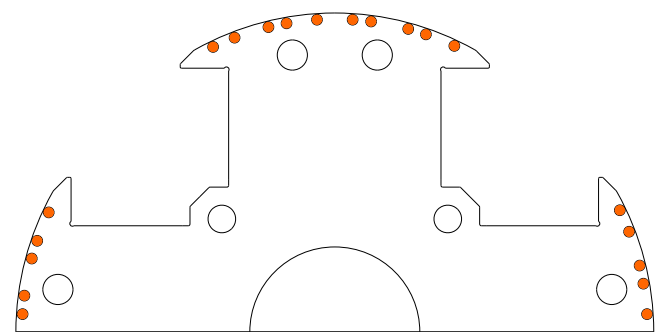

Fig. 15. Improved damper cage solution for reduced losses and improved THD.

A comparison between actual and optimised damper bar losses in one salient pole (Pole 1 in Fig. 1) is shown in Fig. 16. The bar numbering goes counter-clockwise looking at the investigated salient-pole. One may observe a considerable ohmic loss reduction in bars 3,6 and 7. While losses have not been reduced in all the bars (i.e. 4 and 5), the total amount of losses has been strongly reduced. Fig. 17 shows a comparison between the currents in bar 6 of the original and the improved damper winding, where it can be observed that a strong current reduction has been achieved with the optimal solution. The

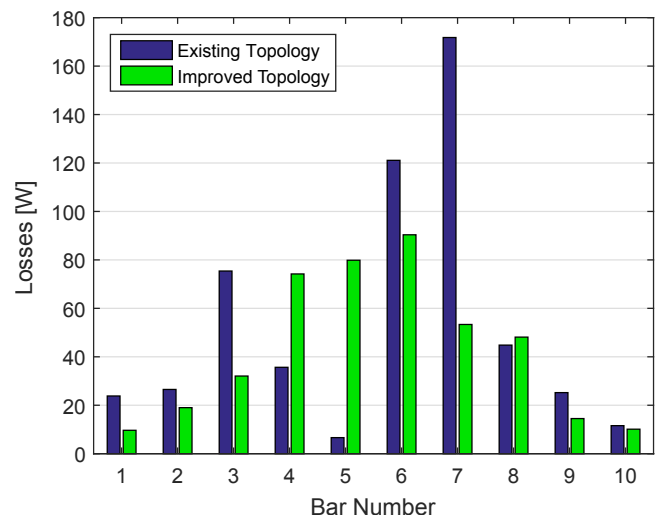

Fig. 16. Bar losses comparison between the actual and the improved design at no-load operating condition.

same qualitative results are obtained at full-load operation. In Fig. 18, ohmic losses in each bar are compared for the existing and the optimal topology. As well as at no-load condition, there are few bars in the new cage with higher losses than the existing design, i.e. bars 4 and 5, but the total loss in the whole damper

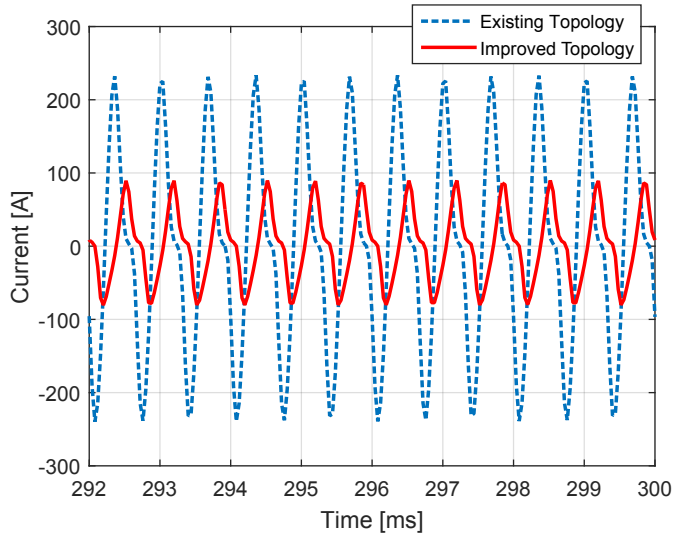

Fig. 17. Currents in bar 6: comparison between existing and optimal damper cage at no-load operating condition.

cage has been reduced. Also, it can be noticed that the most loaded bars are the ones on the right-hand pole tip, due to the armature reaction. A summary of the comparison between

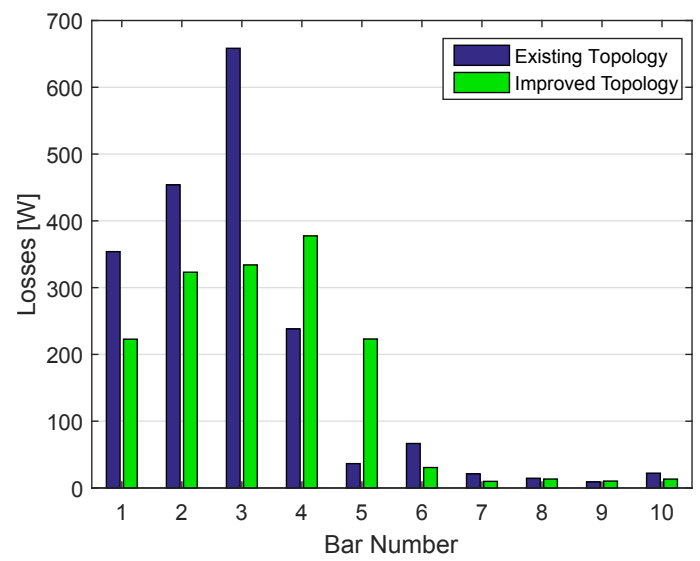

Fig. 18. Bar losses comparison between the actual and the improved design at full-load operating condition.

the two topologies is shown in Table III. The selected solution achieves a loss reduction of about $30 \%$ at no-load and $35 \%$ at full-load condition. By analysing the optimal pattern of Fig. 15 and the results shown in Fig. 16 and 18, it can be concluded that losses are minimised because the presence of a graded airgap (not constant along the tangential direction) make the bars positioned on the pole tips less sensitive to the slot openings. For example, bars 1, 2 and 3 present an increased distance from the stator slots in the proposed design, with respect to the same bars of the existing machine. This has advantages at both noload and full-load, where the same bars are also less affected by the armature reaction field, as they link reduced flux due to their new repositioning.

TABLE III

SUMMARY OF THE IMPROVEMENTS ACHIEVED BY THE IMPROVED TOPOLOGY

\begin{tabular}{cccc}
\hline $\begin{array}{c}\text { Machine } \\
\text { Topology }\end{array}$ & $\begin{array}{c}\text { No-load } \\
\text { loss }\end{array}$ & $\begin{array}{c}\text { Full - load } \\
\text { loss }\end{array}$ & THD \\
\hline Current & $2.331 \mathrm{~kW}$ & $9.653 \mathrm{~kW}$ & $2.573 \%$ \\
Improved & $1.642 \mathrm{~kW}$ & $6.224 \mathrm{~kW}$ & $2.552 \%$ \\
\hline
\end{tabular}

\section{CONSIDERATIONS ON THE DYNAMIC PARAMETERS}

In Section V, it was shown that a significant loss reduction can be achieved by designing the damper cage in such a way that the bars are not uniformly spaced over the rotor surface 
(see Fig. 15). With this technique the voltage THD can also be maintained approximately the same as the current SG, without reverting to disruptive techniques such as rotor and/or stator skewing.

However, for a comprehensive design of the damper cage, the dynamic performance of the machine also needs to be studied and analysed. This is required in order to keep the characteristic values (transient and sub-transient time constants and reactances) within acceptable range and thus avoid intolerable mechanical stresses resulting from excessive currents that occur during electrical disturbances at or near the SG stator terminals.

In order to determine the parameters that describe the dynamic behaviour of the machine, a sudden three-phase SC test was performed (see Fig. 19) and the dynamic parameters evaluated according to the procedure described in [37]. The prototype generator studied in this paper was tested at rated output voltage. In the test simulation was performed by coupling

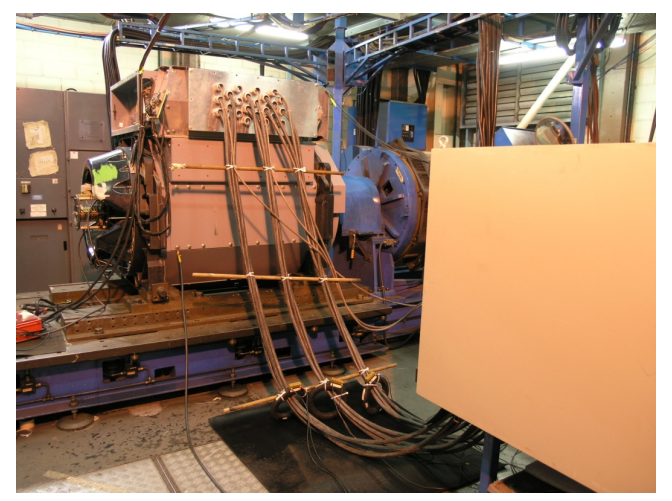

Fig. 19. Set-up for the sudden three-phase short-circuit test carried out on the original $4 M V A \mathrm{SG}$.

stator and rotor external circuit to the FE model, as shown in Fig. 20, where the resistances $R$ are equal to a practical infinite value in order to simulate the no-load condition. These resistances are then short-circuited by the switches $S 1$ and $S 2$ at the SC time instant. The field winding supply source $V_{f}$ is such that is able to provide the rated voltage at no-load operation. This simulation set-up was used for both the existing SG and the optimal machine, aiming to:

- further validate the FE model of the SG analysed in this paper;

- show that the un-conventionally displaced damper cage topology does not modify the dynamic behaviour of the SG.

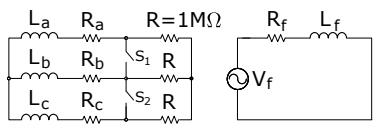

Fig. 20. Circuits coupled to FE model for the short circuit test simulation.

A comparison between simulation and experimental results is shown in Fig. 21, where the envelope curves of the SC currents for each phase are shown. A reasonable match between test and simulation of the existing machine is achieved. Besides this, a perfect match between the FE envelope curves of the existing and the improved machine can be observed. Therefore, the optimal damper cage topology, in addition to significantly improving the overall efficiency of the machine, does not modify the dynamic performance of the salient-pole SG studied in this paper.
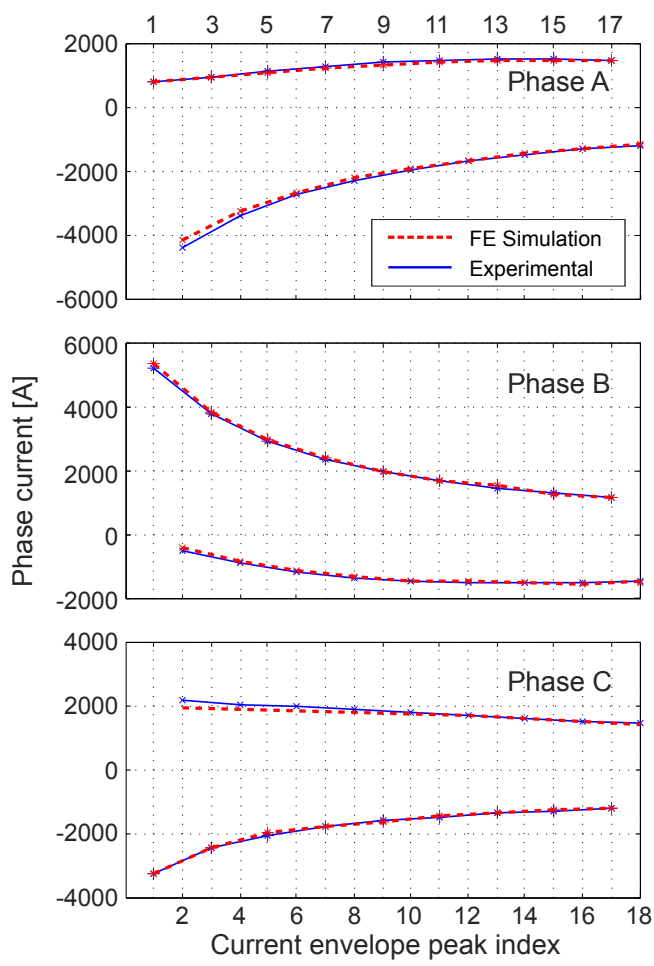

Fig. 21. Envelope curves resulting from the sudden three-phase short-circuit test.

For the sake of completeness and closure of this work, the dynamic parameters of the SG were experimentally evaluated and their values are given in Table IV. These characteristic parameters are usually used to describe the machine's behaviour on sudden short-circuit.

TABLE IV

REACTANCES AND TIME CONSTANTS

\begin{tabular}{c|c|c}
\hline \multicolumn{3}{c}{ Dynamic Parameters } \\
\hline Synchronous Reactance & $X_{d}$ & $2.44 \mathrm{p.u.}$ \\
Transient Reactance & $X_{d}^{\prime}$ & $0.20 \mathrm{p.u.}$ \\
Subtransient Reactance & $X_{d}^{\prime \prime}$ & $0.16 \mathrm{p.u.}$ \\
Transient SC Time Constant & $T_{d}^{\prime}$ & $0.268 \mathrm{~s}$ \\
Subtransient SC Time Constant & $T_{d}^{\prime \prime}$ & $0.0209 \mathrm{~s}$ \\
\hline
\end{tabular}

\section{CONCLUSIONS}

This paper deals with the reduction of damper cage loss and the output voltage total harmonic distortion in a salient-pole SG. It is shown that the damper cage loss, as well as the THD of the output voltage, is strongly affected by the rotor damping bars geometry.

A full and detailed validation of the FE model of a $4 M V A$ synchronous machine is presented at several loading conditions by comparing with experimental results.

A detailed FE sensitivity analysis of the design variables that have high impact on the damper cage losses and no-load voltage THD has been carried out.

An optimal damper cage design for reduced ohmic bar losses and improved output voltage THD is then proposed. This solution lies in replacing a typical uniformly distributed damper cage with a modulated one, and tailoring the position of each bar to reach the desired objectives. The theoretical reasoning behind the concept of modulating the rotor bars is also presented. In order to achieve an optimal geometry, a genetic-algorithmbased-software has been used to investigate the problem. The 
optimal solution achieves a loss reduction of about $30 \%$ at noload and $35 \%$ at full-load condition, whilst maintaining the THD below the critical value of $3 \%$. Also, it has been shown how the improved damper cage topology does not affect the behaviour of the SG in transient conditions.

The results obtained in the paper have shown how this technique is particularly suited for the type of machine considered in this work. However, it is not limited to this particular SG, as it can also be applied to avoid skewing and hence reduce manufacturing cost in smaller alternators. For the sake of completeness and generality, GA-FE-based optimisation results for a $400 \mathrm{kVA}$ generator are also shown in Fig. 22, where improvements in the output voltage THD and damper cage losses can be observed. This technique can be further improved and modified according

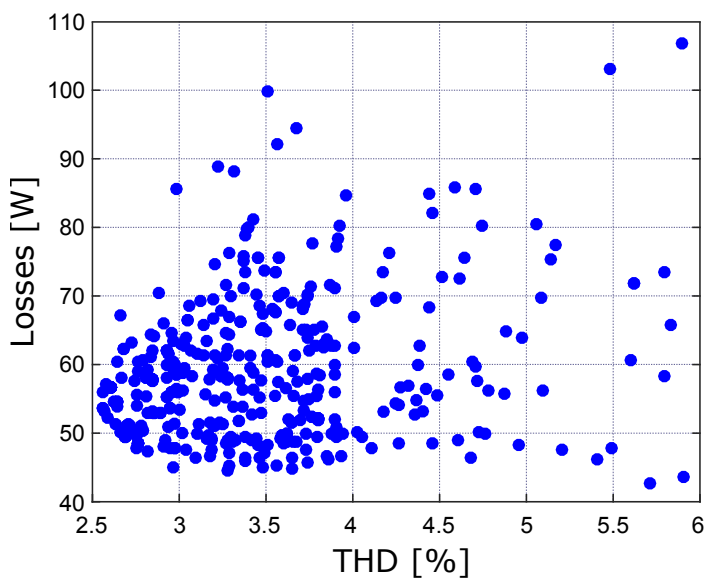

Fig. 22. Optimisation results for the $400 k V A$ generator.

to the specific application which it is intended for. Variants of this technique can include the increase the number of input variables to be considered. For example, in this work only the bars of 1 pole were considered, in order to reduce the computational time of the virtual prototyping process. A second iteration might include consideration of localized modulation, i.e. not repeated over the poles.

\section{REFERENCES}

[1] A. Renjit, M. Illindala, D. Klapp, "Graphical and Analytical Methods for Stalling Analysis of Engine Generator Sets," IEEE Trans. Ind. Appl., vol. 50, pp. 2967-2975, 2014.

[2] A. Griffo, D. Drury, T. Sawata, P. H. Mellor, "Sensorless starting of a wound-field synchronous starter/generator for aerospace applications," IEEE Trans. Ind. Electron., vol. 59, no. 9, pp. 3579-3587, Sep. 2012.

[3] W. Yi, D. M. Ionel, D. Staton, "Ultrafast Steady-State Multiphysics Model for PM and Synchronous Reluctance Machines", IEEE Trans. Ind. Electron., vol. 51, no. 5, pp. 3639-3646, Sep./Oct. 2015.

[4] K. S. Jiji, N. H. Jayadas, C. A. Babu, "FEM-based Virtual Prototyping and Design of Third Harmonic Excitation System for Low-Voltage SalientPole Synchronous Generators,", IEEE Trans. Ind. Electron., vol. 50, no. 3, May/June 2014

[5] D. G. Dorrell, J. K. H. Shek, M. A. Mueller, M. Hsieh, ”Damper windings in induction machines for reduction of unbalanced magnetic pull and bearing wear," IEEE Trans. Ind. Appl., vol. 49, no. 5, pp. 2206-2216, Sep./Oct. 2013.

[6] E. Kimbark, Power System Stability-Volume I. Wiley-IEEE Press, Chapter XIV, pp. 214-246, 1995.

[7] G. Traxler-Samek, T. Lugand, A. Schwery, "Additional losses in the damper winding of of large hydrogenerators at open-circuit and load conditions," IEEE Trans. Ind. Electron., vol. 57, no. 1, pp. 154-160, Jan. 2010.

[8] M.M. Liwshitz, "Harmonics of the salient pole synchronous machine and their effects part III. Differential leakage of the damper winding with respect to the main wave. Current distribution in the damper bars," Trans. Amer. Instr. Elect. Eng. Part III Power App. Syst., vol. 77, no. 3, pp. 462-469, Apr. 1958.
[9] I.M. Canay, "Calculation of negative-sequence losses and negativesequence resistance of turbogenerators," IEEE Trans. Power App. Syst., vol. PAS-94, no. 3, pp. 764-773, May 1975

[10] H. Karmaker, A.M. Knight, "Investigation and simulation of fields in large salient-pole synchronous machines with skewed stator slots," IEEE Trans. Energy Convers., vol. 20, no. 3, pp. 604-610, Sep. 2005.

[11] A.M. Knight, H. Karmaker, K. Weeber, "Use of a permeance model to predict force harmonic components and damper winding effects in salientpole synchronous machines," IEEE Trans. Energy Convers., vol. 17, no. 4, pp. 709-716, Dec. 2002.

[12] P. H. Connor, S. J. Pickering, C. Gerada, C. N. Eastwick, C. Micallef, C. Tighe, "Computational fluid dynamics modelling of an entire synchronous generator for improved thermal management," Electric Power Applications, IET, vol. 7, no. 3. pp. 231-236, 2013.

[13] A. Boglietti, A. Cavagnino, D. Staton, M. Shanel, M. Mueller, C. Mejuto, "Evolution and modern approaches for thermal analysis of electrical machines," IEEE Trans. Ind. Electron., vol. 56, no. 3, pp. 871-882, Mar. 2009.

[14] S. Jordan, C. Manolopoulos, J. M. Apsley, "Winding configurations for five-phase synchronous generators with diode rectifiers," IEEE Trans. Ind. Electron., vol. 63, no. 1, pp. 517-525, Jan. 2016.

[15] E. Wallin, M. Ranlof, U. Lundin, "Design and construction of a synchronous generator test set-up," presented at the Int. Conf. Electrical Machines (ICEM), Rome, Italy, Sep. 6-8, 2010, Paper RF-008982.

[16] A. Tessarolo, C. Bassi, D. Giulivo, "Time-stepping finite-element analysis of a 14-MVA salient-pole shipboard alternator for different damper winding design solution," IEEE Trans. Ind. Electron., Vol. 59, No. 6 , pp. 2524-2535, June 2012.

[17] A. Schwery, G. Traxler-Samek, E. Schmidt, "Application of a transient finite element analysis with coupled circuits to calculate the voltage shape of a synchronous generator," in Proc. CEFC, 2002, pp. 92-95.

[18] De-wei Zhang, Yuan-jun Peng, Zhen-nan Fan, "No-load voltage waveform optimization and rotor heat reduction of tubolar hydro-generator", presented at the Int. Conf. Electrical Machines and Systems (ICEMS), Beijing, China, Aug. 20-13, 2011, pp. 1-6.

[19] G. Traxler-Samek, T. Zickermann, A. Schwery, "Cooling airflow, losses and temperatures in large air-cooled machines," IEEE Trans. Ind. Electron., vol. 57, no. 1, pp. 172-180, Jan. 2010.

[20] Cheng, David K., "Field and Wave Electromagnetics", 2nd ed., AddisonWesley, 1989.

[21] S. A. Swann and J. W. Salmon, "Effective resistance and reactance of a rectangular conductor placed in a semi-closed slot," Proc. IEE, vol. 110, no. 9, pp. 1656-1662, Sep. 1963.

[22] N. Bianchi, " Electrical Machine Analysis Using Finite Elements," 2005.

[23] C. P. Steinmetz, "On the law of hysteresis," AIEE Trans., pp. 364, 1892. Reprinted under the title "A Steinmetz contribution to the ac power revolution," introduction by J. E. Brittain, in Proc. IEEE, vol. 72, pp. 196221.

[24] A. Boglietti, A. Cavagnino, D. M. Ionel, M. Popescu, D. A. Staton, S. Vaschetto, "A General model to predict the iron losses in PWM InverterFed Induction Motors", IEEE Trans. Ind. Appl., vol. 46, No. 5, Sept. 2010, pp 1882-1890.

[25] B. Marcusson, U. Lundin, "Finite-Element Calculation of 3-D Transient Electromagnetic Field in End Region and Eddy- Current Loss Decrease in Stator End Clamping Plate of Large Hydrogenerator" IEEE Trans. Ind. Appl., vol. 62, No. 12, Dec. 2015, pp. 7331-7338.

[26] B. Marcusson, U. Lundin, "Axial Magnetic Fields at the Ends of a Synchronous Generator at Different Points of Operation" IEEE Trans. Magn., vol. 51, No. 5, Feb. 2015.

[27] S. Wang, Z. Zhao, L. Yuan, and B. Wang, "Investigation and analysis of the influence of magnetic wedges on high voltage motors performance," in Proc. IEEE VPPC, Sep. 2008, pp. 1-6.

[28] P. M. Lindh, D. Vinnikov, J. J. Pyrhnen, P. Ponomarev, "Influence of Wedge Material on Losses of a Traction Motor with Tooth Coil Windings," IECON Conference, October, 2013 Vienna.

[29] A. Biebighauser, A. Ghita, "Rotor for a rotating electrical machine", Patent WO 2014/202985 A2, Dec. 24, 2014.

[30] D. A. Kocabas, "Novel winding and core design for maximum reduction of harmonic magnetomotive force in AC motors", IEEE Trans. Magnetics, vol. 45, no. 2, pp. 735-745, Feb. 2009.

[31] M. M. Rahimian and K. Butler-Purry, "Modeling of synchronous machines with damper windings for condition monitoring," in Proc. IEEE Int. Elect. Mach. Drives Conf., Miami, FL, USA, May 2009, pp. 577-584.

[32] A. Tessarolo, "Accurate computation of multiphase synchronous machine inductances based on winding function theory," IEEE Trans. Energy Convers., vol. 27, no. 4, pp. 895-904, Dec. 2012.

[33] P. Bolognesi, "A Mid-Complexity Analysis of Long-Drum-Type Electric Machines Suitable for Circuital Modelling", in Proc. ICEM 2008 Conf., paper n. 99.

[34] Ma Cong, Qu Liyan "Multiobjective Optimization of Switched Reluctance Motors Based on Design of Experiments and Particle Swarm Optimization," IEEE Trans. Energy Convers., vol. 30, No. 3, Sept. 2015. 
[35] M. A. Khan, I. Husain, M. R. Islam, J. T. Klass, ”Design of experiments to address manufacturing tolerances and process variations influencing cogging torque and back EMF in the mass production of the permanentmagnet synchronous motors," IEEE Trans. Ind. Appl., vol. 50, no. 1, pp. 346-355, Jan./Feb. 2014
[36] Poles S., Technical Report 2003-006, "MOGA-II An improved MultiObjective Genetic Algorithm."

[37] IEEE 115, Guide for Test Procedures for Synchronous Machines Part I - Acceptance and Performance Testing Part II-Test Procedures and Parameter Determination for Dynamic Analysis, 2009. 